\title{
Pro Domo Sua: Narratives of Sexual Abstinence
}

\author{
Fabio Indìo Massimo Poppi ${ }^{1,2}$ D
}

Accepted: 16 September 2020 / Published online: 7 October 2020

(c) The Author(s) 2020

\begin{abstract}
Sexual abstinence is generally interpreted as a health-promotion practice, in particular to avoid HIV/AIDS risk and unwanted pregnancy and parenthood. This paper offers insight into narratives and interactional fantasizing that challenge common conceptions of sexual abstinence. The data come from several interviews and group discussions conducted in a netnographic context, altogether involving 21 European, middle- and upper-middle-class women who have never engaged in sexual intercourse or who are sexually experienced but have discontinued sexual practices for some reason. The women's narratives and interactional fantasizing about sexual abstinence can reveal positive societal effects such as opposing sexualisation of culture and pressure for sex, but also more individual perspectives such as promoting self-esteem, psycho-physical well-being, work productivity and career prospects. Narratives and interactional fantasizing seem to play an important role in examining how sexual abstinence can impact society, especially people's perception of sexuality and gender roles.
\end{abstract}

Keywords Ethnography · Interview $\cdot$ Interactional fantasizing $\cdot$ Narrative $\cdot$ Online Sexual abstinence

\section{Introduction}

Like any other social phenomenon, sexual abstinence is seen through the lens of values, beliefs, ideas, and practices. These aspects can help to understand reasons and motives behind sexual abstinence and reveal important insights about society. As sexuality is characteristic of people, deep comprehension of any sex-related topic can help comprehension of society as a whole. In order to connect personal views to more general ones about sexual abstinence, research needs to handle tools within dynamics of micro-macro levels of analysis. In other words, a view endorsed here is

Fabio Indìo Massimo Poppi

fabioimpoppi@me.com

$1 \quad$ University of Łódź, Łódź, Poland

2 Sechenov Moscow University, Moscow, Russian Federation 
that people's personal narratives are representative of broader, societal views on the issue.

Many aspects of sexual abstinence have been largely overlooked. In previous studies, sexual abstinence has been generally seen as a practice attributed to low and lower middle class teenagers, adolescents and young women, who avoid unwanted pregnancy and parenthood and for HIV/AIDS risk reduction. This study aims to investigate the role that sexual abstinence plays among more adult, middle- and upper-middle-class women. I place a particular emphasis on: (i) the motivations that lead women to sexual abstinence; (2) the possible benefits that sexual abstinence accrues within social, psychological and emotional domains and, (3) insights into gender roles and intimate relationship expectations affected by sexual abstinence. While narrative studies usually rely on stories about present and past experiences, here also the role of fantasies about sexual abstinence has been taken into account. In this way, the study benefits both from a wider participant selection and from stories that consider imaginary events to expand the understanding of sexual abstinence towards unexplored dimensions.

\section{Narrative Analysis and Sexual Abstinence}

The notion of a narrative-or a story-describes a universal form of human knowledge that consists of a sequence of thematically and temporally related events (see Frank 2012). Although narratives play a central role in communicating knowledge and information in society, they do not necessarily reflect reality; rather, narratives can create and shape the way individuals perceive and affect the social realities and phenomena they appertain to (see Jäger 2001; Tamboukou 2008; Poppi and Castelli Gattinara 2018).

As De Fina and Georgakopoulou (2011) observe, narratives are necessarily situated and embedded in social dynamics and this is reflected in how narratives are constantly used as social sense-making devices. Thus, the connection between narratives and social dynamics has been the object of numerous studies by sociologists and discourse analysts. Contributions such as that by De Fina (2008) show how people make sense of social realities and phenomena and how narratives reflect the values, beliefs, ideas and practices of the society tout court. For this reason, social situations such as family dinners (Ochs and Taylor 1992), therapeutic sessions (Fasulo 1999), workplace meetings (Holmes 2006), legal interviews (Trinch 2003), trials (Harris 2005), and classroom events (Baquedano Lopez 2001) have been analyzed through a micro-macro perspective The investigation of narratives in very specific contexts (micro-level) has allowed analysts to offer general insights (macro-level) into the social realities in which these contexts occur (De Fina 2008). In a similar way, narratives have also been studied as an analytical device that helps explore how people represent widespread social phenomena and how cultural narratives (macro-level) differ from more individual elaborations (micro-level).

Specifying the distinction between cultural and individual narratives, Loseke (2007) defines the former as narratives that operate, that imbue abstract and general representations and that help to simplify and understand the society. These 
narratives - also called master narratives - are usually the product of multiple authors, storylines and forms (Loseke 2007). Cultural narratives are widely considered dominant in a specific culture as they represent socially acceptable viewpoints (see Thommesen 2010; Perrier et al. 2013). The study of cultural narratives as standard views (see Snajdr 2013) has gone hand in hand with more individual narratives that characterize the micro-level of narrative use. Specifically, Ochs and Capps (1996) claim that personal narratives can reflect individuals' viewpoints and treatment of events and social phenomena, and show individual differences in personality characteristics and life experiences (McLean et al. 2007). In recent contributions (e.g. Poppi 2019; Poppi and Sandberg 2020), narratives of specific phenomena - sex work and sexual promiscuity - are analysed to show how negatively connoted dominant representations can be contrasted with several more personal narratives that have positive implications, shifting from the level of cultural narratives to more individual ones.

In the light of this, two aspects are of particular interest for the micro and macro analysis of narratives. First, narratives allow the researcher to ascertain something general about the society starting from close observations of specific social realities and phenomena; second, narratives help us to understand people's perceptions of social realities and phenomena in terms of more socially acceptable and dominant representations.

In general terms, narratives have been studied as single-voiced processes about real events. However, recent studies have started to consider the role of narratives with imaginary contents produced by different individuals within the same communicative situation (Poppi 2019). Joint fantasizing describes a practice of shared construction of imaginary realities (Stallone and Haugh 2017; Poppi, forthcoming) characterized by what Vincent and Castelfranchi (1981: 755) define as 'a fictional or imaginary world, where $\mathrm{X}$ is true' despite being fully aware that in 'the real world $\mathrm{X}$ is false (a pretense)'. In order to be regarded as joint fantasizing, it is necessary that the two or more subjects act as 'if they were doing something that they are not actually, really, or seriously doing' (Clark and Van Der Wege 2001: 783). Additionally, joint fantasizing needs to be developed with the intent to talk about scenarios that are not real, or that belong to future/hypothetical worlds (Leary 1980; Stallone and Haugh 2017; Poppi 2019). Such scenarios take the form of joint fantasizing. This practice-also labelled as fantasy layering (Clark 1996), joint fictionalisation (Kotthoff 2007) or 'fictional narratives' (Leary 1980) - is then characterised by a merger of mutual interaction and unreality. As joint fantasizing concerns people's collaborative construction based on each other's contributions (Hall 1974: 35), contributions are produced in an open-ended way (Kotthoff 2007: 135).

As some studies have shown (Poppi 2019; Poppi and Sandberg 2020), in ordinary social interactions, participants tend to build fantasising scenarios singlehandedly in reference to topics commenced by other interlocutors, and across turns in the interactions to which they contribute. For this reason, this paper takes into account a notion broader than joint fantasizing labelled "interactional fantasizing" (Poppi 2019; forthcoming), while subjects do not necessarily need to "chime in" (Bertrand and Priego-Valverde 2011: 337), but they "can enact interactional fantasizing by simply inducing or inspiring other participants to produce narratives 
about imaginary events" (Poppi, forthcoming). Interactional fantasising stands at the crossroad between the concept of fantasy (Miller and Sperry 1988) and interactional narratives (Nelson 2003). A crucial property of interactional fantasizing is its capacity to reveal the values, ideas and practices of a society starting from micro-level interactions and can contribute to the understanding of macro-social phenomena (see Poppi and Castelli Gattinara 2018).

In the last few years, the analysis of individual narratives in specific social phenomena have also been applied to sex-related practices. Sexual orientation (e.g. Murray 2014), sexual promiscuity (Poppi 2019), sexual harassment, sex scandals and pedophilia (e.g. Cavanagh 2008; Fasting and Sand 2015), as well as human trafficking (e.g. Kaye 2007; Albright and D'Adamo 2017), sexual abstinence (see Kahn 2006) and sex work (see Poppi and Sandberg 2020) are just some of the topics in which personal narratives have been identifed and discussed. The reason for the interest about this research trend is inherently caused by the specificity of sex and sexuality (see Poppi 2019). Every sex-related concept is greatly affected by a wide range of contextual, social and cultural factors (see Ford and Beach 1951; Simon 2017). Contextual, social and cultural factors often experienced by individuals can be conveyed in the form of narratives, which allow individuals to reveal values, beliefs, ideas, and practices. Moreover, sex and sexuality are also the domain of fantasies (e.g. Ziegler and Conley 2016), including shared fantasies (Noorishad et al. 2017). Hence, fantasies may be used as a tool with which to examine people's beliefs about sex and sexuality in narrative studies.

Among the many sex-related topics that have been analyzed, sexual abstince is one of those which has not received much attention in narrative studies. In general terms, sexual abstinence is the voluntary avoidance of sexual intercourse. As the notion of sexual intercourse shows a wide range of meanings, researchers have started to provide more fine-tuned definitions. Horan et al. (1998) defined abstinence as refraining from vaginal, anal, or oral sex, while other researchers have operationally narrowed the definition of abstinence to not engaging in vaginal or anal penetration only (see Lefkowitz et al. 2004; Bogart et al. 2007). In the various attempts to provide consistent definitions, some approaches have tried to identify those activities that people perform when describing sexual abstinence. What emerges from a comprehensive study conducted by Byers et al. (2007) is that students' understanding of sexual abstinence includes deep kissing and other nongenital intimate behaviors such as showering together and breast play. As this definition proved to be too limiting in selecting participants for this study, the notion of sexual abstinence that is used here is in line with Lefkowitz et al. (2004) and Bogart et al. (2007). Additionally, sexual abstinence has also been described in terms of primary and secondary abstinence: specifically, primary abstainers are people who have never engaged in sexual intercourse, while secondary abstainers are people who are sexually experienced but have discontinued sexual practices for some reason. (see Loewenson et al. 2004). Additionally, It can be seen that sexual abstinence has been extensively studied in the light of the different motivational factors that can motivate it.

According to a large number of studies, the main factors that seem to foster sexual abstinence depend on personal values and religious beliefs (see Gardner 2011; Landor and Simons 2014) and sex education (see Santelli et al. 2006) received at 
school and at home. Regardless of the gender differences, sexually abstinent people have more conservative values and greater religious involvement (Paul et al. 2000; Lefkowitz et al. 2004; Rasberry and Goodson 2009). As Byers et al. (2009: 667) points out, "high quality sexual health education is more likely to include a discussion of the sexual health risks associated with a range of sexual behaviors as well as to define abstinence operationally".

Sexual abstinence has been often studied in relation to the avoidance of unwanted pregnancy and parenthood (see Martyn and Hutchinson 2001) and for HIV/AIDS risk reduction (see Basen-Engquist et al. 2001; Oladepo and Fayemi 2011; Gelibo et al. 2013; Najarkolaei et al. 2013). The role of HIV/AIDS prevention is also reported in one of the very few studies based on the analysis of narratives of sexual abstinence. In this contribution, Kahn (2006) uses narratives to analyze the decisionmaking strategies of sexual abstinence among adolescent girls. Specifically, the narratives reveal that the participants attempt to challenge and counter sexual norms holding for their community, the norms characterized by high levels of sexual promiscuity. Another contribution about the role of narratives (Haglund 2006) defines two main themes_- "Development of Sexual Identity" and "Challenges to Abstinence"-in which unique and common experiences about sexual abstinence are reported. Here, Haglund detailed the following narratives (Kahn 2006: 4-7). Regarding the "Development of Sexual Identity", the author states that abstinence can be motivated by (1) the wish to live a "Christian life and live according to Bible principles, (2) the attempt to be different from other people who have promiscuous sexuality, (3) the avoidance of negative consequences and trouble, (4) the inclination to to obey and not disappoint their mothers and (5) the preservation of friendships instead of involvement in other type of relationships. In addition, Haglund (2006: 7-9) lists the three primary sources of challenge to abstinence. Specifically, subjects reported abstinence as a tool (6) to avoid acts of sexual harassment, (7) to maintain a positive social image and (8) to avoid teasing about not having sex and group conversations about intimate matters.

This contribution takes as its point of departure Haglund's observations (2006) but suggests a number of amendments that may lead to a wider range of insights. Together with narratives, interactional fantasizing is considered. In this way, the understanding of sexual abstinence will incorporate real experiences and envisaged possibilities built through interactional fantasizing. While the vast majority of the studies about sexual abstinence rely on teenagers, adolescents and young adults (see Kahn 2006; Kabiru and Ezeh 2007; Haglund 2006; Izugbara 2007; Byers, Henderson and Hobson 2009; Ott and Pfeiffer 2009), this study addresses a different age group, namely adults. The literature about the understanding and representations of sexual abstinence reports on participants coming from Africa or African American low income communities (see Cleland and Ali 2006; Kahn 2006; Haglund 2006; Kabiru and Ezeh 2007; Childs et al. 2008). Although these studies address essential issues such as HIV/AIDS and unwanted pregnancy, which seem to characterize particular cultural groups, narratives and interactional fantasizing produced by European, middle- and upper-middle-class women could show interpretations of sexual abstinence that appear to have been overlooked until today. 


\section{Methods}

For the present contribution, data are developed from online interviews with 21 Western and Estern European women recruited from personal $(n=6)$ and extended personal networks $(n=15)$. The recruitment did not follow any systematic selection but was based on word-of-mouth referrals and included any women that showed willingness to talk about their sexual abstinence in the context of an academic research. The conditions for the participation in the study are listed as follows: (1) middle- or upper-middle-class, (2) being sexually abstinent for at least two years and (3) declaring a neutral or favorable attitude towards sexual abstinence.

The women involved in the study-ranging from 25 to 55 years of age (average 37,9)—were from Italy (12), Russia (2), Poland (2), Germany (1), France (1), Croatia (1), Albania (1) and Ukraine (1). Although the selection of the participants does not consider the country of origin, the idea of working with a wide number of countries affords a broader perspective on how women of different nationalities perceive sexual abstinence. As the individual views of the women from the different countries are by no means incompatible, this could offer a coherent intercultural representation of womens' perceptions of sexual abstinence and promote the transferability of these narratives to other contexts and be helpful for further studies.

Semi-structured interviews were conducted between May and September 2018 and between March and April 2020. Although a number of similar questions were asked to all the participants, the interviews did not present any rigid structure that could limit the conversations. The questions to the participants addressed issues related to sexual abstinence and the implications that it could have on emotional, personal, social and economic dimensions. However, a set of questions was repeated in each interview. These include: (I) What are the main motivations that have led you to opt for sexual abstinence? (II) What are the main socia, relational and emotional differences that you have experienced after choosing sexual abstinence?, (III) Does sexual abstinence have positive or negative aspects that are somehow common among people?, (IV) Are there any consequences of sexual abstinence in emotional, personal, social and economic dimensions. For the single-voice narratives, one-to-one interviews $(n=12)$ were conducted in writing through Skype or Telegram, an instant messaging application; for the interactional fantasizing the data collection was conducted through a combination of writing and multi video-chat using Skype $(n=9)$. The participation in the two settings, one-to-one or interactional interviews, was based on three main criteria. First of all, the decision to use only Italian participants for the interactional fantasizing was based on the necessity to set a context where communication could take place as naturally as possible in the participants' native language. In addition, every woman of the Italian group was asked whether she wanted to be interviewed in a one-to-one context or together with other participants. The multi video-chat sessions were divided into four different groups of variable composition where each respondent was involved for a minimum of one and a maximum of three 
sessions. For the part dedicated to one-to-interviews narratives, the anonymity of the participants varied from visual anonymity to full anonymity (see Keipi and Oksanen 2014), depending on the information participants provided; however, for the interactional fantasising the anonymity among the participants could not be guaranteed as most of the participants knew each other. In any case, the present study does not provide any information about the participants or that could determine their identity.

Based on an initial reading of all interviews, the author coded the verbalizations using the codes that those contents that show (i) the motivations that lead women to sexual abstinence; (2) the possible benefits that sexual abstinence produce within social, psychological and emotional domains and, (3) what sexual abstinence reveals about gender roles and intimate relationship expectations. The study followed general qualitative-research analysis standards (Kvale and Brinkmann 2009). The two coders advanced a series of theme-based typology (see Sandberg et al. 2019) of stories about sexual abstinence that revolve around specific themes. Moving from from more general to more specific themes, I suggest: "Unicity narratives", "Alternative narratives", "Recovering narratives", "Social pressure", "Career narratives" and "Femicide narrative". These different narrative themes present some overlaps. This is due to the ideal-typical nature of narrative themes which can be considered generalizations made for the sake of clarity and better understanding of the role of sexual abstinence.

The participants' extracts in the analysis section are quoted verbatim in the same form as they occurred during the interviews. The Italian participants verbalized in Italian, while the other participants in English only. The translations of the messages and the audio-transcriptions include the stylistic imperfections. While the single voice narratives do not show any reference to the participant, interactional fantasizing is reported with sequential reference (e.g. i, ii, iii) to the person who is speaking. The interviewer's contributions are reported in italics, while his notes are reported in square brackets.

\section{Narratives of Sexual Abstinence}

The analysis has made possible to identify a number of narratives and interactional fantasizing which represent women's different understandings and the meanings the women assign to it. While the content of some of the interviews overlaps the content of the narratives described by Haglund (2006), other ones seem to show novel insights and these new insights are the main focus of attention.

\section{Unicity Narratives}

Similar to what Haglund (2006) describes, the so-called "unicity narratives" refer to those narratives that see sexual abstinence as one of the key aspects that help to develop unique specific social values and distinctive personality traits. Five 
single-voice narratives recount how unicity is based on the variety of self-directed evaluations and expectations about social relationships.

\section{Extract 1}

- It's a very frequent feeling that nobody or very few people would deserve me. And that's why I retired.

Yes.

If we can say so.

\section{Extract 2}

- I know people and I know men and I know that most of them cannot win me Things are complicated.

But I definitely prefer to feel unique rather than wasting my own value.

\section{Extract 3}

- Some women prefer to give themselves, also for boredom or loneliness

Some women, not many to be honest, have a different idea.

The wish to feel different and special for someone special prevails.

\section{Extract 4}

- I don't want to give myself like that, like an obvious thing

These things are becoming too meaningless.

And I think meanings still count.

I mean.

I like the idea to be valued and considered different.

I am not saying that I am really special in any way, but I fancy some special treatment!

\section{Extract 5}

- We are nobody in our professional lives, and even in our families sometimes

Society tends to step over us.

Yes, yes.

Life can be difficult and feeling special would be an amazing sensation.

That's why I wait for some Mr. Right, that's it.

The idea of unicity is recurrent in the understanding of sexual abstinence (see Martyn and Hutchinson 2001; Haglund 2006; Steven et al. 2014). The way teenagers, adolescents and young adults consider themselves as worthy of particular consideration is expressed by their own uniqueness and their sense of what was right for them. Here, utterances such as "It's a very frequent feeling that nobody, or very 
few people would deserve me" and "And that's why I retired, But I definitely prefer to feel unique rather than wasting my own value" describe these feelings well among adults, too. However, while for younger women the unicity serves as a motivator for choosing the right partner for their first sexual experiences, in this context unicity also plays a role in secondary abstinence. In particular, women also use unicity as a means to distance themselves from experiences that do not give enough value to their needs ("I like the idea to be valued and considered different. I am not saying that I am really special in any way, but I fancy some special treatment!’). Interestingly, the wish for feeling "different and special" within a private relationship is partly motivated by a broad criticism of the society. The society is perceived in negative terms - in aspects of depersonalization and derealization ("We are nobody in our professional lives, and even in our families sometimes, Society tends to step over us") - and so uniqueness works as a compensatory reaction ("Life can be difficult and feeling special would be an amazing sensation. That's why I wait for some Mr. Right, that's it"). While affirming the necessity for more meaningful relationships, the women also advance a criticism about the way sexuality is usually conceived by their peers. Here, sexual life is considered as a consequence of some motivations ("boredom or loneliness") that contrast with the idea that sexual experiences should be the result of more meaningful reasons ("I don't want to give myself like that, like an obvious thing. These things are becoming too meaningless").

\section{Alternative Pleasure Narratives}

Although sexual pleasure is one of the most common forms of pleasure (Poppi 2019), the interviews show that abstinence can lead to different, alternative forms of pleasure. As these three single-voiced narratives and one interactional fantasizing shows, sexual abstinence can lead women to discover a range of pleasurable activities that otherwise would have been more difficult to experience.

\section{Extract 6}

- Since I have started with a different approach to sex, I feel I have more understanding of what real needs are

Feeling relaxed, meditation, yoga.

Or whatever.

These are alternative pleasures to sex.

It's not that sex is not incompatible with these activities, but dating and sex can be very stressful and I was tired of that.

\section{Extract 7}

- Sexual life forces you to put into discussion your look, your sex appeal, your self-esteem

Let's say I am not a teen anymore!

Not my bad! 
And I am tired of this pressure, so much to handle.

At a certain age doing things for our-selves is way more enriching than doing something that is also for someone else.

\section{Extract 8}

- Since I quit with certain things, my life is richer and even more interesting

I am a different person and I have learned so much I could not even believe I could!

\section{Extract 9}

(i) If I had started earlier

With all this, I would have done more things in life.

(ii) Like you had not done enough

(i) I know I know

But I lost time chasing wrong people.

(iii) That's a matter of age

(i) I would have developed myself much more and done much more

That's for sure.

And, well.

I would have started to do things I do now.

And so other things I am going to learn soon.

My well-being comes first now!

(iii) Well-being comes first indeed especially because these activities give you real pleasure and nobody can deny that!

Unlike what has been presented in previous studies, sexual abstinence is also seen as a way of optimising one's time and getting involved in activities that otherwise would have been more difficult to do. In the light of this, women think that being actively involved in sexual relationships requires an amount of time and energy that would be better spent on other activities. Yoga and meditation are considered prototypical ways to be involved in......as they allow the women to develop "alternative pleasures" that would place self-esteem and psychophysical well-being as a priority ("It's not that sex is not incompatible with these activities, but dating and sex can be very stressful and I was tired of that"). Sexual abstinence is regarded as a way of reducing the level of social pressure regarding physical appearance and self-esteem ("Sexual life forces you to put into discussion your look, your sex appeal, your self-esteem") and as a way of according more value to time ("(i) If I had started earlier. With all this, I would have done more things in life"). Regardless of a subjective perspective, alternative pleasure narratives-in a similar way to the unicity ones-show that sexual abstinence operates against the dictates and obligations of the society. The contemporary view of sexual life posits a certain amount of pressure on women ("And I am tired of this pressure, so much to handle") to the point that abstinence becomes a gateway and opportunity to promote different 
sources of satisfaction and fulfillment ("Since I quit with certain things, my life is richer and even more interesting").

\section{Recovering Narratives}

Recovering narratives refer to the content of interviews that see sexual abstinence as a way to regain emotional well-being after having experienced negative romances. In the three single-voiced narratives and two interactional fantasizing, sexual abstinence is represented as a way to distance oneself not only from past suffering, but also from the likelihood of potential troubles.

\section{Extract 10}

- The last one was a hard hit for me and I thought I could not make it I made it, fair enough.

But I have been doing everything to prevent new experiences like that to happen.

Maybe I will change my mind one day.

But I am not ready yet.

I mean.

And yes, abstinence is helping a lot!

\section{Extract 11}

- I am refraining from sex because I don't want to meet other jerks

And jerks are really everywhere.

As I am still recovering, sex is out of the table now.

I guess I can say that.

\section{Extract 12}

- It's really important to take care of our emotional stability and some sexual isolation can make a great difference.

\section{Extract 13}

(iii) There are experiences that can leave a sign

And what can we do?

(v) Just stop doing certain things, that's the first step.

(vi) The bigger the jerk the longer the abstinence needs to be. It's almost mathematical.

(v-iii) Ahahah.

(vi) When I will give men another chance, if things go bad, I will shut down everything forever! 
(iii) Uhm.

(vi) Radical, radical.

\section{Extract 14}

(vii) If I hadn't decided to take a break for one reason, there would have been another reason anyway

(ii) Reasons are subjective, but feeling good is what that matters and what I need.

(vii) I am glad about what happened with XXXXX.

Because I understand what I really needed.

(i) Now maybe you would be seen as more normal, but certainly as less happy.

(vii) That's what that matters to me!

(i) Nothing is more important.

(vii) And yet.

(ii) Things always go in some way or the other.

As the narratives and interactional fantasizing suggest, abstinence plays a crucial role in the establishment of a period of recovery from adverse experiences in which sexuality played a major role. The women report experiences in which sexual abstinence serves to establish distance from people that caused suffering and/ or stress ("I am refraining from sex because I don't want to meet other jerks. And jerks are really everywhere"). Sexual abstinence seems to enact a sort of recovery based on emotional stability ("It's really important to take care of our emotional stability, and some sexual isolation can make a great difference") and of a better understanding of personal needs ("Reasons are subjective, but feeling good is what matters and what I need"; "Because I understand what I really needed"). Interestingly, sexual abstinence as a form of recovery does not ____ only in relation to past experiences, but also in terms of future possibilities ("The bigger the jerk the longer the abstinence needs to be, It's almost mathematical"). What emerges is that abstinence is not only a matter of values, practices, or beliefs, but also a coping strategy for eventual negative social experiences. In this sense, sexual abstinence acquires a connotation which has not yet been described in the relevant literature.

\section{Social Pressure Narratives}

Similar to what Haglund suggests (2006), narratives about social pressure describe the attempt by women to avoid the social pressure that they should have sex at any cost, as they were not aware of the pleasure they were missing. Here, two singlevoiced narratives and the cases of two interactional fantasizing represent different ways in which women withstand from the social pressure of being sexually active. 


\section{Extract 15}

- I find this really annoying, especially from close friends

One should be free, without judgement.

The more I feel pressure, the more I get stubborn on my position.

This is conformism and.

And just routine.

I am against these things.

\section{Extract 16}

- Social pressure is out there, I cannot deny it

It looks people just want you to have sex or talk about it.

This is simply unbearable sometimes.

I'd prefer different conversations to this.

And some people are really unidimensional.

I escape from this, from boredom.

These people are just boring.

That's what they are.

And you know what, I'd rather be more and more isolated than.

Than sharing.

Sharing all this!

\section{Extract 17}

(iv) how can you?

(i) Some people are really obsessed and that's an understatement!

(ii) One day you will lose your temper.

(i) Yes, one day I will tell them to fuck off. And I will feel much better.

(ii) It's crazy how people don't have other perspectives and thoughts.

(i) it's an obsession and it's a very private matter for me.

And this idea of sharing private matters is just wrong.

(iv) I agree, I agree.

(ii) Tell them to fuck off is really the think and I hope I will have a similar chance one day.

\section{Extract 18}

(xii) After this decision I cut many relationships

And of course I created new ones.

(xv) That's good, that's good.

(xi) Good.

(xv) There always new social opportunities. 
(xii) I need different people anyway, people I can really talk to.

So many other dimensions to explore.

(xi) and enjoy life, be relaxed!

(xii) I dream to have people in my life that are not obsessed and so on.

(xi) Better for a better life.

The social pressure narratives described by Haglund (2006) consider the pressure coming from romantic partners and female peers. In these two cases, sex is regarded as a crucial activity from which it is difficult to distance oneself, particularly because of the connotation of normality that characterizes it and the tension that arises when abstinence is made explicit. Here, sexual abstinence also becomes a topic that helps the women to mark social interactions with peers as undesirable. This is particularly clear in extracts such as "It looks people just want you to have sex or talk about it. This is simply unbearable sometimes. I'd prefer different conversations to this" and "(i) Yes, one day I will tell them to fuck off. And I will feel much better. (ii) It's crazy how people don't have other perspectives and thoughts". If, on the one hand, sexual abstinence exposes women to social pressure and to a consequent wish to establish distance from those peers that cause it, on the other hand, abstinence also makes the conditions for developing new relationships (Oswald and Russell 2006). This constructive aspect of abstinence emerges in an interactional fantasizing in which the women imagine having more relaxed social experiences. Specifically, "(xii) I need different people anyway, people I can really talk to. So many other dimensions to explore. (xi) and enjoy life, be relaxed! (xii) I dream to have people in my life that are not obsessed and so on". As the women report, sexual abstinence can certainly reduce the number of social interactions ("And you know what, I'd rather be more and more isolated than, Than sharing, Sharing all this!"), but also induce them to seek and create better social relationships. Interestingly, as one woman states, social pressure does not produce any effect. Conversely, peers' sharing and talking about sexuality and criticizing abstinence makes abstainers more rooted in their practice ("One should be free, without judgement. The more I feel pressure, the more I get stubborn on my position"). This aspect suggests that sexual abstinence feeds on a strong component of deliberate nonconformity ("This is conformism and. And just routine. I am against these things"), an aspect that seems to have been overlooked in previous studies.

\section{Career Narratives}

Career narratives refer to those productions in which the women see sexual abstinence as a way to focus on their professional development. As most of the narratological studies about sexual abstinence consider young participants, career narratives could only emerge with adults because of the importance of their careers at later stages in life. In these examples, three single-voiced narratives are discussed.

\section{Extract 19}

- When you free your life from sex, you can do more goal-oriented 
I am getting better at my job.

That's a fact.

And sex is more of a simple act, it's a process.

And it can be very long.

And what's left, then?

Time is the key.

My recent promotions and even my productivity.

Well.

Less distractions!

\section{Extract 20}

- Getting more involved in my career is what I want now

And nothing can stop me now.

I am glad I am done with certain things.

I could not take anymore and I have other priorities.

\section{Extract 21}

- You always take breaks and focus on your career

To a certain extent, I would like to be normal again.

But I am really at a crucial moment of my life and I don't want any distraction. I am fine.

My future is more important.

One of the main benefits of discussing sexual abstinence in adult women is the impact of this practice on their professional lives. As it is possible to see in alternative pleasures and recovering narratives, sexuality is reported as an activity with high social, psychological and emotional costs. Stress, pressure and demands can also affect the time and psychophysical resources that women could dedicate, for instance, to their careers and professional development. One of the key aspects of career narratives is the awareness of the complexity of sexual life and how this can be somehow in competition with professional life. This is explicit in "When you free your life from sex, you can do more goal-oriented, I am getting better at my job. That's a fact", especially because it is reported how abstinence has positive consequences in terms of productivity and promotions in the workplace ("My recent promotions and even my productivity. Well."). Besides better time management ("Time is the key") and focus ("Less distraction"; "But I am really at a crucial moment of my life and I don't want any distraction"), sexual abstinence seems to work as a motivator and priority marker, allowing the women to move from more private matters to more external ones ("Getting more involved in my career is what I want now [...] I could not take anymore and I have other priorities"). Sexual abstinence plays a central role in promoting future prospects and conditions for enriching and developing experiences ("Getting more involved in my career is what I want now. And nothing can stop me now"). Just like for unicity and social pressure narratives, career narratives also see sexual abstinence as a means of going beyond the status quo and aim at self-enhancing visions of oneself. 


\section{Femicide Narratives}

Although abstinence has been often regarded as a way of promoting a safer lifestyle, these two interactional fantasizing shows that adult women see refraining from the sexual dimension as a way to achieve a sense of safety from the tragedy of femicide.

\section{Extract 22}

(iii) I think that getting away of sex can be also safe

(v) That's also for the femicide!

(iii) Sure, indeed

(vi) I cannot imagine being involved with someone violent

(iii) Someone like that cannot certainly be with someone who does not want to get laid

(v) Ahaha, that's bad to say

(iii) I think that's true

Those are animals!

(v) You cannot be with one of those animals for sure

(iii) Sex protects you in a way

Especially the lack of it!

(vi) Well said, well said

\section{Extract 23}

(vii) Women need to self-distance themselves from certain people

(vi) Especially men..

(i) Only men!

(vi) Could you imagine living with someone like that?

(vii) That's something important

A relationship based on other deep emotions.

(vi) That would be safer for sure!

(i) Totally agree!

(vii) That's something ideal, almost impossible to achieve

(i) These things can be life-changing!

(vii) One relation like that is safer and healthier, enriching, but you need a saint

(vi) A saint that just comes to your life

And moves towards other things.

And make you feel safe.

(i) That cannot be women killed just like that

It's unbearable! 
The interaction fantasizing reported above shows that sexual abstinence is regarded as an effective measure for preventing femicide, the killing of one or more females by one or more males because they are female (Russell 2012). As this phenomenon is largely present within intimate relationships (see Glass et al. 2008), abstinence is used as a way to reduce exposure to partners. In this sense, sexual activities are implicitly represented as the condition that could put the women in risky relationships (“(vi) I cannot imagine being involved with someone violent (iii) Someone like that cannot certainly be with someone who does not want to get laid"). This belief - that combines the femicide risk in intimate relationships with a sexual component - also describes abstinence as making any partner less prone to committing violent acts ("A relationship based on other deep emotions. (vi) That would be safer for sure!. (i) Totally agree!"). Just like for the reduction in contracting diseases and maintaining better health conditions (see Gelibo, Belachew and Tilahun 2013; Najarkolaei et al. 2013), sexual abstinence is also conceived as an effective tool for preventing gender-based violence (“(v) You cannot be with one of those animals for sure (iii) Sex protects you in a way. Especially the lack of it!"). Also in this case, sexual abstinence becomes not only a matter of private intimate choices, but a tool for preventing negative outcomes that affect the society.

\section{Discussion and Conclusion}

This analysis of narratives and interactional fantasizing has brought to light some aspects of sexual abstinence that deserve focused attention, the aspects that would have been challenging to obtain with a different methodological apparatus. Specifically, unlike previous contributions that have presented sexual abstinence primarily as a practice that promotes health and responsible parenthood, here the importance of its impact on sociality also emerges. In general terms, sexual abstinence and critical views on sex are shown in three interrelated ways.

First, sexual abstinence is represented as a means that encourages women to look for more meaningful relationships. The women in this study see sexual activity as an expression of attitudes that aim to trivialize human value and dismiss their uniqueness ("But I definitely prefer to feel unique rather than wasting my own value"). Second, sexual activity becomes an all-embracing activity that does not allow women to find and engage in other activities that could better express their personality. In this sense, their sexual abstinence would leave space for other forms of leisure and engagement ("Since I quit with certain things, my life is richer and even more interesting. I am a different person and I have learned so much I could not even believe I could!"). Third, the preponderance of sexuality as a topic and as lifestyle in social relationships motivates women to be more selective in their choice of friends and partners, to the point of giving an inherent value even to forms of social retreat ("And some people are really unidimensional. I escape from this, from boredom").

As these aspects suggest, sexual abstinence and the criticisms of mundane sexuality can be interpreted as a wider opposition to the so-called "sexualisation of culture" (Gill 2012). At least for the Western society, the sexualisation of culture refers to the progressive saturation of sexual representations and discourses (see 
also Poppi and Dynel 2020). The "sexualisation of culture" presents sex as a "big story" that permeates the society. As Attwood states (2006: 77), the sexualisation of culture presents a number of different aspects such as: "a contemporary preoccupation with sexual values, practices and identities; the public shift to more permissive sexual attitudes; the proliferation of sexual texts; the emergence of new forms of sexual experience; the apparent breakdown of rules, categories and regulations designed to keep the obscene at bay; [and the] fondness for the scandals, controversies and panics around sex". In the context of private and social relationships, the sexualisation of culture represents the substrate for that pressure for sex that has emerged in many extracts ("And I am tired of this pressure, so much to handle"). Pressure for having sex is seen as socially acceptable (Oswald and Russell 2006) by norms in which "no" means "keep trying" (Holland et al. 2004) or even where "no means yes" (Osman 2003). Among other things, as Katz and Tirone (2010: 738) state, these norms have been interpreted in terms of the "higher rates of men's use of sexually coercive tactics relative to women (Struckman-Johnson et al. 2003) and, in turn, the higher rates of sexual compliance among heterosexual women relative to men (Impett \& Peplau 2003)". Here, sexual abstinence works not only as a way to express a rejection of the sexualisation of culture-especially by looking for different and more diversified interactional activities - but also to embrace a view that sex can also cause different forms of stress and pressure ("dating and sex can be very stressful and I was tired of that", "Sexual life forces you to put into discussion your look, your sex appeal, your self-esteem").

Besides this critical attitude towards social norms, sexual abstinence has also been interpreted in the light of defensive attitudes. Although the role of sexual abstinence in contrasting the onset of diseases and pregnancy-related concerns has been well-documented (ee Martyn \& Hutchinson 2001; Basen-Engquist et al. 2001; Oladepo and Fayemi 2011; Gelibo, Belachew and Tilahun 2013; Najarkolaei et al. 2013), little is known about forms of prevention in the emotional and social sphere. Specifically, the extracts show that sexual abstinence serves as a practice that not only helps one to recover emotionally from adverse experiences in which sexuality played a major role but also reduces the chances of these experiences happening again. In this sense, sexual abstinence allows women to avoid those relationships that are perceived as emotionally riskier because of the presence of sexual activity. As sexual activities are considered a way of encountering potentially disruptive people ("I am refraining from sex because I don't want to meet other jerks. And jerks are really everywhere"), abstinence helps to reduce these possibilities. In a more dramatic way, the preventative function is also expressed for femicide. Here, femicide not only represents a tragic societal problem but also a consequence of sexually-based relationships ("Someone like that cannot certainly be with someone who does not want to get laid"). In these transcriptions, the women seem to assume that the natural settings for femicide is a conventional private life. Just like the sexualisation of culture and the consequent pressure for sex, stories about femicide also grant access to the inherent societal problems that are directly caused by the primary role that sex plays. The women distance themselves from sexuality not only as a private practice, but also in terms of their attempts to challenge social and cultural problems that can hardly be solved in other ways. Similar to the societal 
criticisms of mundane sexuality and femicide, these insights have also been possible because of the advanced age of the female interviewees, a dimension that is also of interest to the proactive and enhancing aspects of abstinence.

In line with what Haglund presents (2006), sexual abstinence represents safety and protection from harmful experiences more directly, the extracts also show different, and overlooked aspects. As sexual abstinence has been reported to ensure more emotional stability, together with giving more value to time, it is not surprising that women find different activities to dedicate themselves to. Besides social and leisure activities that could represent alternatives to sex ("meditation, yoga. These are alternative pleasures to sex"), women reports that abstinence can even boost work productivity and career prospects. Sex and those related activities such as dating seem to limit women's professional development. This limitation likely comes from those forms of social pressure that have been discussed above, and whose presence can have an impact on the professional level. As some extracts show, sexual abstinence plays a positive role, a proactive role that allows women to benefit from a different view of private life and develop socially and economically ("When you free your life from sex, you can do more goal-oriented. I am getting better at my job"). Sexual abstinence empowers women by easing those social pressures that often hover over gender roles.

In line with De Fina (2008), the importance of analyzing different forms of narratives in order to ascertain general insights about society (macro-level) starting from very specific interactions (micro-level), the stories about sexual abstinence also show perspectives on some defined topics can tell us much about the functioning of society.

\section{Compliance with Ethical Standards}

Conflict of interest The author declares that he has no conflict of interest.

Ethical Standards All procedures performed in studies involving human participants were in accordance with the ethical standards of the institutional and/or national research committee and with the 1964 Helsinki declaration and its later amendments or comparable ethical standards.

Informed Consent Informed consent was obtained from all individual participants included in the study.

Open Access This article is licensed under a Creative Commons Attribution 4.0 International License, which permits use, sharing, adaptation, distribution and reproduction in any medium or format, as long as you give appropriate credit to the original author(s) and the source, provide a link to the Creative Commons licence, and indicate if changes were made. The images or other third party material in this article are included in the article's Creative Commons licence, unless indicated otherwise in a credit line to the material. If material is not included in the article's Creative Commons licence and your intended use is not permitted by statutory regulation or exceeds the permitted use, you will need to obtain permission directly from the copyright holder. To view a copy of this licence, visit http://creativeco mmons.org/licenses/by/4.0/. 


\section{References}

Albright, E., \& D'Adamo, K. (2017). The media and human trafficking: a discussion and critique of the domi- nant narrative. Human Trafficking Is a Public Health Issue (pp. 363-378). Berlin: Springer.

Attwood, F. (2006). Sexed up: Theorizing the sexualization of culture. Sexualities, 9(1), 77-94.

Baquedano Lopez, P. (2001). Creating social identities through doctrina narratives. In A. Duranti (Ed.), Linguistic Anthropology: A Reader (pp. 343-358). Oxford: Blackwell.

Basen-Engquist, K., Coyle, K. K., Parcel, G. S., Kirby, D., Banspach, S. W., Carvajal, S. C., et al. (2001). Schoolwide effects of a multicomponent HIV, STD, and pregnancy prevention program for high school students. Health Education \& Behavior, 28(2), 166-185.

Bertrand, R., \& Priego-Valverde, B. (2011). Does prosody play a specific role in conversational humor? Pragmatics \& cognition, 19(2), 333-356.

Bogart, L. M., Collins, R. L., Ellickson, P. L., \& Klein, D. J. (2007). Are adolescent substance users less satisfied with life as young adults and if so, why? Social Indicators Research, 81(1), 149-169.

Byers, E. S., Henderson, J., \& Hobson, K. M. (2009). University students' definitions of sexual abstinence and having sex. Archives of Sexual Behavior, 38(5), 665-674.

Cavanagh, S. (2008). Sexing the teacher: School sex scandals and queers pedagogies. Seattle: University of Washington Press.

Childs, G., Moneyham, L., \& Felton, G. (2008). Correlates of sexual abstinence and sexual activity of low-income African American adolescent females. Journal of the Association of Nurses in AIDS Care, 19(6), 432-442.

Clark, H. H. (1996). Using language. Cambridge: Cambridge University Press.

Clark, H. H., \& Van Der Wege, M. M. (2001). Imagination in discourse. In D. Schiffrin, D. Tannen, \& H. H. Hamilton (Eds.), The handbook of discourse analysis (pp. 772-786). Malden, MA: Blackwell.

Cleland, J., \& Ali, M. M. (2006). Sexual abstinence, contraception, and condom use by young African women: a secondary analysis of survey data. The Lancet, 368(9549), 1788-1793.

De Fina, A. (2008). Who tells which story and why? Micro and macro contexts in narrative. Text \& Talk, 28(3), 421-442.

De Fina, A., \& Georgakopoulou, A. (2011). Analyzing narrative: Discourse and sociolinguistic perspectives. Cambridge: Cambridge University Press.

Fasting, K., \& Sand, T. S. (2015). Narratives of sexual harassment experiences in sport. Qualitative Research in Sport, Exercise and Health, 7(5), 573-588.

Fasulo, A. (1999). Life narratives and the construction of normality. In W. Maiers, B. Bayer, B. Duarte Esgalhado, R. Jorna, \& E. Schraube (Eds.), Challenges to theoretical psychology. Concord: Captus Press.

Ford, C., \& Beach, F. (1951). Patterns of Sexual Behavior. New York: Harper and Rowe.

Frank, A. W. (2012). Practicing dialogical narrative analysis. In J. A. Holstein \& J. F. Gubrium (Eds.), Varieties of narrative analysis (pp. 33-52). London: Sage.

Gardner, C. J. (2011). Making chastity sexy: The rhetoric of evangelical abstinence campaigns. California: University of California Press.

Gelibo, T., Belachew, T., \& Tilahun, T. (2013). Predictors of sexual abstinence among Wolaita Sodo university students. South Ethiopia. Reproductive health, 10(1), 18.

Gill, R. (2012). The sexualisation of culture? Social and Personality Psychology Compass, 6(7), 483-498.

Glass, N., Laughon, K., Rutto, C., Bevacqua, J., \& Campbell, J. C. (2008). Young adult intimate partner femicide: An exploratory study. Homicide Studies, 12(2), 177-187.

Hall, F. (1974). Conversational joking: A look at applied humour. In J. McDowell (Ed.), Folklore Annual of the University Folklore Association 6 (pp. 24-45). Austin, TX: University of Texas Press.

Haglund, K. (2006). Understanding sexual abstinence in African American teens. MCN: The American Journal of Maternal/Child Nursing, 31(2), 86-92.

Harris, S. (2005). Telling stories and giving evidence. In J. Thornborrow \& J. Coates (Eds.), The sociolinguistics of narrative (pp. 215-237). Amsterdam: John Benjamins.

Holland, J., Ramazanoglu, C., Sharpe, S., \& Thompson, R. (2004). The male in the head: Young people, heterosexuality, and power. London: Tufnell Press.

Holmes, J. (2006). Workplace narratives professional identity and relational practice. In A. De Fina, D. Schirin, \& M. Bamberg (Eds.), Discourse and identity. Cambridge: Cambridge University Press.

Impett, E. A., \& Peplau, L. A. (2003). Sexual compliance: Gender, motivational, and relationship perspectives. Journal of Sex Research, 40, 87-100. 
Izugbara, C. O. (2007). Constituting the unsafe: Nigerian sex workers' notions of unsafe sexual conduct. African Studies Review, 50(3), 29-49.

Jäger, S. (2001). Discourse and knowledge: Theoretical and methodological aspects of a critical discourse and dispositive analysis. In R. Wodak \& M. Meyer (Eds.), Methods of critical discourse analysis. London: SAGE Publications.

Kabiru, C. W., \& Ezeh, A. (2007). Factors associated with sexual abstinence among adolescents in four sub-Saharan African countries. African Journal of Reproductive Health, 11(3), 111.

Kahn, L. (2006). Narratives of sexual abstinence: A qualitative study of female adolescents in a Cape Town community. Social Dynamics, 32(1), 75-101.

Katz, J., \& Tirone, V. (2010). Going along with it: Sexually coercive partner behavior predicts dating women's compliance with unwanted sex. Violence Against Women, 16(7), 730-742.

Kaye, K. (2007). Sex and the unspoken in male street prostitution. Journal of Homosexuality, 53(1-2), 37-73.

Kotthoff, H. (2007). Oral genres of humor. Pragmatics Quarterly Publication of the International Pragmatics Association (IPrA), 17(2), 263-296.

Kvale, S., \& Brinkmann, S. (2009). InterViews: Learning the craft of qualitative research inter-viewing (2nd ed.). Thousand Oaks, CA: Sage.

Landor, A. M., \& Simons, L. G. (2014). Why virginity pledges succeed or fail: The moderating effect of religious commitment versus religious participation. Journal of child and family studies, 23(6), 1102-1113.

Leary, J. P. (1980). Recreational talk among white adolescents. Western Folklore, 39(4), 284-299.

Lefkowitz, E. S., Gillen, M. M., Shearer, C. L., \& Boone, T. L. (2004). Religiosity, sexual behaviors, and sexual attitudes during emerging adulthood. Journal of sex research, 41(2), 150-159.

Loewenson, P. R., Ireland, M., \& Resnick, M. D. (2004). Primary and secondary sexual abstinence in high school students. Journal of Adolescent Health, 34(3), 209-215.

Loseke, D. R. (2007). The study of identity as cultural, institutional, organizational, and personal narratives: Theoretical and empirical integrations. The Sociological Quarterly, 48(4), 661-688.

Martyn, K. K., \& Hutchinson, S. A. (2001). Low-income African American adolescents who avoid pregnancy: Tough girls who rewrite negative scripts. Qualitative Health Research, 11(2), 238-256.

McLean, K. C., Pasupathi, M., \& Pals, J. L. (2007). Selves creating stories creating selves: A process model of self-development. Personality and social psychology review, 11(3), 262-278.

Miller, P. J., \& Sperry, L. L. (1988). Early talk about the past: The origins of conversational stories of personal experience. Journal of Child Language, 15(2), 293-315.

Murray, D. A. (2014). The (not so) straight story: Queering migration narratives of sexual orientation and gendered identity refugee claimants. Sexualities, 17(4), 451-471.

Najarkolaei, F. R., Niknami, S., Aminshokravi, F., Tavafian, S. S., Jafari, N. A. J., \& Golabchi, A. (2013). Promoting sexual abstinence intention among female university students: A quasi-experimental study. Journal of research in medical sciences: the official journal of Isfahan University of Medical Sciences, 18(1), 37.

Nelson, K. (2003). Self and social functions: Individual autobiographical memory and collective narrative. Memory, 11(2), 125-136.

Noorishad, P. G., Levaque, E., Byers, E. S., \& Shaughnessy, K. (2017). More than one flavour: University students' specific sexual fantasies, interests, and experiences. The Canadian Journal of Human Sexuality, (aop), pp 1-17.

Ochs, E., \& Taylor, C. (1992). Family narrative as political activity. Discourse \& Society, 3(3), 301-340.

Oladepo, O., \& Fayemi, M. M. (2011). Perceptions about sexual abstinence and knowledge of HIV/AIDS prevention among in-school adolescents in a western Nigerian city. BMC public health, 11(1), 304.

Osman, S. L. (2003). Predicting men's rape perceptions based on the belief that "no" really means "yes". Journal of Applied Social Psychology, 33(4), 683-692.

Oswald, D. L., \& Russell, B. L. (2006). Perceptions of sexual coercion in heterosexual dating relationships: The role of aggressor gender and tactics. Journal of Sex Research, 43(1), 87-95.

Ott, M. A., \& Pfeiffer, E. J. (2009). "That's nasty" to curiosity: Early adolescent cognitions about sexual abstinence. Journal of Adolescent Health, 44(6), 575-581.

Paul, C., Fitzjohn, J., Eberhart-Phillips, J., Herbison, P., \& Dickson, N. (2000). Sexual abstinence at age 21 in New Zealand: The importance of religion. Social Science \& Medicine, 51(1), 1-10.

Perrier, M. J., Smith, B. M., \& Latimer-Cheung, A. E. (2013). Narrative environments and the capacity of disability narratives to motivate leisure-time physical activity among individuals with spinal cord injury. Disability and Rehabilitation, 35(24), 2089-2096. 
Poppi, F. I. M. (2019). Omnia vincit amor: Narratives of sexual promiscuity. Sexuality \& Culture, 139, $1-24$.

Poppi, F. I. M. (forthcoming). Sancte et sapienter: Joint fantasizing as the interactional practice of micro and macro contextual understanding. Pragmatics and Society.

Poppi, F. I. M., \& Dynel, M. (2020). Ad libidinem: Forms of female sexualisation in RoastMe humour. Sexualities. https://doi.org/10.1177/1363460720931338.

Poppi, F. I., \& Gattinara, P. C. (2018). Aliud pro alio: Context and narratives within a neo-Nazi community of practice. Journal of Language and Politics, 17(4), 552-572.

Poppi, F. I., \& Sandberg, S. (2020). A bene placito: Narratives of sex work. Narrative Inquiry, 30(2), 294-315.

Rasberry, C. N., \& Goodson, P. (2009). Predictors of secondary abstinence in US college undergraduates. Archives of Sexual Behavior, 38(1), 74-86.

Russell, D. E. (2012). Defining femicide. In Introduction speech presented to the United Nations Symposium on Femicide. Vienna: UN Symposium, Liaison Office.

Sandberg, S., Tutenges, S., \& Pedersen, W. (2019). Drinking stories as a narrative genre: The five classic themes. Acta Sociologica, 62(4), 406-419.

Santelli, J., Ott, M. A., Lyon, M., Rogers, J., Summers, D., \& Schleifer, R. (2006). Abstinence and abstinence-only education: A review of US policies and programs. Journal of Adolescent health, 38(1), $72-81$.

Simon, W. (2017). Sexual conduct: The social sources of human sexuality. Abingdon-on-Thames: Routledge.

Snajdr, E. (2013). Beneath the master narrative: Human trafficking, myths of sexual slavery and ethnographic realities. Dialectical Anthropology, 37(2), 229-256.

Stallone, L., \& Haugh, M. (2017). Joint fantasising as relational practice in Brazilian Portuguese interactions. Language \& Communication, 55, 10-23.

Stevens, R., Gilliard-Matthews, S., Nilsen, M., Malven, E., \& Dunaev, J. (2014). Socioecological factors in sexual decision making among urban girls and young women. Journal of Obstetric, Gynecologic \& Neonatal Nursing, 43(5), 644-654.

Struckman-Johnson, C., Struckman-Johnson, D., \& Anderson, P. B. (2003). Tactics of sexual coercion: When men and women won't take no for an answer. Journal of Sex Research, 40, 76-86.

Tamboukou, M. (2008). Reimagining the narratable subject. Qualitative Research, 8(3), 283-292.

Thommesen, H. (2010). Master narratives and narratives as told by people with mental health and drug problems. Journal of Comparative Social Work, 2010(1), 1-16.

Trinch, S. (2003). Latinas' narratives of domestic abuse. Amsterdam/Philadelphia: John Benjamins.

Vincent, J., \& Castelfranchi, C. (1981). On the art of deception: How to lie while saying the truth. In J. Verschuren (Ed.), Parret H, Sbisà M. Amsterdam: Possibilities and limitations of pragmatics: Proceedings of the conference on pragmatics. John Benjamins.

Ziegler, A., \& Conley, T. D. (2016). The importance and meaning of sexual fantasies in intimate relationships. The psychology of love and hate in intimate relationships (pp. 29-45). Berlin: Springer.

Publisher's Note Springer Nature remains neutral with regard to jurisdictional claims in published maps and institutional affiliations. 